\title{
The Age for Surveillance Capitalism. The Fight for a Human Future at the New Frontier of Power de Shoshana Zuboff
}

The Age for Surveillance Capitalism. The Fight for a Human Future at the New Frontier of Power by Shoshana Zuboff

Giacomo Buoncompagni

Universidad de Macerata - Italia

Macerat, Italia

giacomo.buoncompagni@libero.it

\section{A NEW YORK TIMES NOTABLE BOOK OF THE YEAR}

\section{THE AGE OF}

SURVEILLANCE

CAPITALISM

THE FIGHT FOR

A HUMAN FUTURE

AT THE NEW

FRONTIER OF POWER

SHOSHANA

ZUBOFF
"Groundbreaking, magisterial, alarming.... Unmissable."

Shoshana Zuboff

The Age for Surveillance Capitalism. The Fight for a Human Future at the New Frontier of Power

PublicAffairs, 2019. 714 págs.
The Age of Surveillance Capitalism es un libro que se aprecia por la extensión, así como por el contenido en la línea de aquellos libros que quieren y pueden hacer una valiosa contribución a la promoción de una cultura capaz de evitar la reducción de la experiencia a comportamientos estereotipados y condicionados. Ojalá su mensaje se convierta en objeto de estudio y consulta para las políticas culturales y sociales. La profecía de un mundo de usuarios inconscientes presupone que este conocimiento no salga de la esfera esotérica de esa misma élite intelectual que, en cambio, como hace Shoshana Zuboff, propone convertirlo en un principio de "lucha".

La experiencia humana es ahora materia prima libre que se transforma en datos de comportamiento y que luego se vende como "productos de predicción", en un nuevo mercado que es el de los mercados de comportamiento de futuro, donde operan empresas que sólo están ansiosas por conocer nuestro comportamiento futuro.

Conceptos importantes como estos pueden leerse en el último libro de Shoshana Zuboff The Age for Surveillance Capitalism. The Fight for a Human Future at the New Frontier of Power (Profile Books, 2019).

El libro presenta una visión de una sociedad distópica, dibujando un escenario desgraciadamente actual y no futurista de las consecuencias de la revolución digital que estamos viviendo. 
En esta era hay un nuevo nombre: el capitalismo de vigilancia. En realidad, el término es nuevo, pero ha sido tomado de otras vertientes, siendo ya fue utilizado por J. Bellamy Foster y R.W. McChesney en un artículo aparecido en 2014 en la histórica Monthly Review. A su entender, esa expresión denotaba una especie de deseo insaciable de datos resultante de la progresiva financiarización de la economía. Zuboff, como experta en humanidades, lo entiende de forma muy diferente.

En el capitalismo de vigilancia, de hecho, se apropian los datos sobre el comportamiento humano, tanto en línea como fuera de ella. Es fácil imaginar a quién se refiere Zuboff: principalmente a Google, que se considera el creador de este nuevo capitalismo.

Sobre todo, el capitalismo de vigilancia es devastador porque corre el riesgo de provocar la desaparición de la humanidad, entendida como una forma humana de razonar y comportarse, de la que la autonomía y la dignidad son rasgos distintivos. El capitalismo de la vigilancia, escribe Zuboff utilizando un paralelismo bastante aterrador, corre el riesgo de hacer a la humanidad lo que el capitalismo industrial hizo a la naturaleza.

El capitalismo de vigilancia se alimenta de la explotación no sólo del trabajo humano, recordando rápidamente la visión de Marx, sino de toda la experiencia humana. Y con él llega una nueva forma de poder que Zuboff, de nuevo para subrayar la novedad del presente, llama instrumental. Este poder permite conocer el comportamiento humano e influir en él, en beneficio de los demás. Su poder no procede de las armas ni de los ejércitos, sino de una arquitectura computacional de dispositivos inteligentes, de cosas y espacios conectados entre sí, de inteligencias conectivas y colectivas.

Por lo tanto, el capitalismo de vigilancia debe ser combatido no sólo por razones históricas -es monopólico, viola la privacidad- sino también, y, sobre todo, porque reduce el comportamiento humano a una mercancía y permite un enriquecimiento extraordinario a través de su comercio. Un capitalismo que no se contenta con automatizar el flujo de información sobre nosotros, sino que pretende automatizarnos.

A la hora de evaluar el capitalismo de vigilancia que mercantiliza la experiencia humana, sería muy útil compararlo con las prácticas de consumo que parecen ir en la dirección opuesta y que luchan por sobrevivir, con los consumidores que están bien concienciados y a los que muchos querrían pedir más en términos de comportamiento de mercado orientado a la consecución de objetivos sociales y no sólo a la satisfacción material inmediata.

La autora no sólo se refiere a la venta de perfiles que pueden utilizarse para la publicidad personalizada en línea, sino que se refiere a otros sectores, como los seguros, el comercio, las finanzas y un conjunto cada vez más amplio de empresas de bienes y servicios que quieren estar presentes en estos nuevos y rentables mercados. También nos invita a recordar que las debilidades cognitivas, que son defectos de nuestra racionalidad, pueden ser explotadas más fácilmente una vez que se conocen los datos del comportamiento de los individuos.

A este respecto, parece útil reflexionar sobre el significado de términos como "persuasión" y “manipulación”, y un buen punto de partida en este último sentido podría ser lo que sostiene Cass R. Sunstein "Los manipuladores suelen explotar la ignorancia o las 'debilidades' de comportamiento de las personas evitando estimular su capacidad de reflexión y deliberación”. Sunstein, afirma que, “Los manipuladores suelen explotar la ignorancia o las 'debilidades' de comportamiento de las personas evitando solicitar su capacidad de reflexión y deliberación".

El reconocimiento de las diferentes implicaciones de estos dos tipos de comportamiento, y una mayor precisión en este sentido, podría conducir 
a un juicio más articulado del capitalismo de vigilancia, así como a una base más sólida de sus verdaderos excesos y distorsiones. Además -y este es un punto importante desde el punto de vista económico- permitiría una mejor comparación de los costes y beneficios de dicho mercado a nivel de sistema, y no a nivel del operador individual. No se sabe nada de los costos y beneficios globales de estos mercados, y no se puede saber nada si no se averigua primero lo que ocurre realmente en los mercados de comportamientos futuros.

Encontramos rasgos similares en el pensamiento de Harari, ya que no sabemos qué forma tendrá el mercado laboral en 2030 o 2040. Ya hoy no tenemos ni idea de qué enseñar a las nuevas generaciones. La mayor parte de lo que se aprende hoy en la escuela será probablemente irrelevante cuando tengan cuarenta años. Harari expresa así una concepción de la educación que ya ha bajado sus armas frente al capitalismo global. Esta concepción, combinada con el cientificismo que mencioné anteriormente, socava profundamente los análisis futuristas de estos autores.

¿Estamos acaso ante una paradoja/error histórico global?

Mientras tanto, partamos de aquí, de encontrar una forma común de entender la expresión "capitalismo de vigilancia”, acuñada por Shoshana Zuboff. Esta expresión condensa efectivamente dos conceptos: el de un nuevo capitalismo, alternativo al industrial de los siglos pasados, y el de un nuevo sistema de poder basado en el control del comportamiento individual.

Una cosa, por tanto, queda ciertamente clara en las palabras de la socióloga, la realidad descrita en Zuboff se reduce a un entorno virtual, totalmente informatizado, en el que no hay circunstancias ni encuentros fortuitos.

Todo esto nos invita a reflexionar sobre cómo una posible "racionalización de las relaciones y las emociones" y un probable control (digital) de los comportamientos humanos cada vez más predecibles conducen a la anulación de la diversidad, de la diversidad cultural, sobre todo. Sin la diversidad cultural, todo parecerá más claro en la comunicación humana, pero en realidad todo será tan igual y monótono. El sentido de la vida comunitaria, de la construcción de relaciones y de todas nuestras actividades sociales se basa en el descubrimiento de la diversidad y en los llamados mecanismos de repetición del Otro a partir de mí (Berger \& Luckman, 1969).

Supervisado y emocionalmente distante, será difícil hacer este "esfuerzo de simpatía" hacia el Otro.

\section{Referencias}

Bellamy Foster, J., and McChesney, R. W. (2014). Surveillance Capitalism. Monopoly-Finance Capital, the Military-Industrial Complex, and the Digital Age. Monthly Review, 66(3). https:// monthlyreview.org/2014/07/01/surveillancecapitalism/

Berger, P., \& Luckmann, T. (1969). La realtà come costruzione sociale. II Mulino.

Harari, Y. N. (2020), The world after coronavirus. Financial Times. https://www.ft.com/ content/19d90308-6858-11ea-a3c91fe6fedcca75

Sunstein, C. R. (2017), \#Republic.Divided Democracy in the Age of Social Media. Princeton University Press. 